\title{
PROSES HIDROLISIS LARUTAN NATRIUM ALUMINAT DENGAN MENGGUNAKAN BIANG ALUMINIUM HIDROKSIDA
}

\author{
Hydrolysis of Natrium Aluminate using Aluminium Hydroxide Seed
}

\author{
HUSAINI, SUGANAL, KUKUH N. HIDAYAT dan STEFANUS S. CAHYONO \\ Puslitbang Teknologi Mineral dan Batubara \\ Jalan Jenderal Sudirman 623 Bandung 40211 \\ Telp. (022) 6030483, Fax. (022) 6003373 \\ e-mail: husaini@tekmira.esdm.go.id
}

\begin{abstract}
ABSTRAK
Aluminium hidroksida $\left[\left(\mathrm{Al}(\mathrm{OH})_{3}\right]\right.$ dapat dihasilkan melalui hidrolisis garam-garam aluminium. Metode pengendapannya dapat dilakukan melalui beberapa cara, antara lain dengan penambahan asam dan penambahan seed $\mathrm{Al}(\mathrm{OH})_{3}$. Pada penelitian ini, hidrolisis larutan natrium aluminat menghasilkan aluminium hidroksida dilakukan dengan menggunakan penambahan seed $\mathrm{Al}(\mathrm{OH})_{3}$. Larutan natrium aluminat yang digunakan diperoleh dari hasil digesting bauksit dengan $\mathrm{NaOH}$ dan seed $\mathrm{Al}(\mathrm{OH})_{3}$ yang sudah dimurnikan dengan hidrosiklon. Tujuan penelitian ini adalah untuk mendapatkan kondisi yang optimum dari proses hidrolisis larutan natrium aluminat menggunakan seed $\mathrm{Al}(\mathrm{OH})_{3}$ dengan variasi waktu dan konsentrasi $\mathrm{Al}_{2} \mathrm{O}_{3}$ dalam larutan natrium aluminat. Kondisi hirdolisis optimum dicapai dengan menggunakan seed sebanyak $41,32 \mathrm{~kg}$ untuk volume larutan natrium aluminat $370 \mathrm{~L}$ dalam waktu 66 jam pada suhu $50-60^{\circ} \mathrm{C}$ yang dapat menurunkan kadar alumina $\left(\mathrm{Al}_{2} \mathrm{O}_{3}\right)$ dari semula $152,91 \mathrm{~g} / \mathrm{L}$ dalam larutan awal menjadi $62,51 \mathrm{~g} / \mathrm{l}$ pada akhir proses atau memberikan persen hidrolisis akhir sebesar 59,12\%. Produk $\mathrm{Al}(\mathrm{OH})_{3}$ yang dihasilkan memiliki komposisi $91,15 \% \mathrm{Al}(\mathrm{OH})_{3}$ dan bisa digunakan sebagai bahan baku pembuatan PAC (Poly Aluminum Chloride) sebagai koagulan.
\end{abstract}

Kata kunci : aluminium hidroksida, seed, hidrosiklon, digesting, hidrolisis

\begin{abstract}
Aluminium hydroxide $\left[\left(\mathrm{Al}(\mathrm{OH})_{3}\right]\right.$ can be obtained by hydrolysis of aluminium salts. The precipitation method may be conducted through several ways such as acid and seed of $\mathrm{Al}(\mathrm{OH})_{3}$ addition. In this reseach, hydrolysis was carried out by using sodium aluminate resulting from digesting of bauxite with $\mathrm{NaOH}$ and seed which had been refined by hydrocyclone. The purpose of this research is to get hydrolisis optimum condition from the reaction of sodium aluminate solution with $\mathrm{Al}(\mathrm{OH})_{3}$ seed using variation of hydrolisis time and alumina concentration in sodium aluminate solution. The optimum condition of hydrolisis was achieved using 41,32 $\mathrm{kg}$ of seed for $370 \mathrm{~L}$ of sodium aluminate solution for 66 hours at the temperature between $50-60^{\circ} \mathrm{C}$ that could reduce alumina content from $152,91 \mathrm{~g} / \mathrm{L}$ in initial solution to be $62.51 \mathrm{~g} / \mathrm{L}$ at final process or provided hydrolisis percentage of $59,12 \%$. Product of $\mathrm{Al}(\mathrm{OH})_{3}$ had chemical composition of $\mathrm{Al}_{2} \mathrm{O}_{3} 91,15 \%$ that can be used as a raw material for PAC (Poly Aluminium Chloride) making as coagulant.
\end{abstract}

Key words: aluminium hydroxide, seed, hydrocyclone, digesting, hydrolisis 


\section{PENDAHULUAN}

Indonesia merupakan negara yang memiliki beraneka ragam mineral yang tersebar di berbagai wilayah Kepulauan Nusantara, salah satunya adalah bauksit $\left(\mathrm{Al}_{2} \mathrm{O}_{3} \cdot \mathrm{xH}_{2} \mathrm{O}\right)$. Dari data Badan Geologi, Kementerian Energi dan Sumber Daya Mineral (ESDM), jumlah keseluruhan sumber daya bijih bauksit di Indonesia mencapai 3,6 milyar ton dengan jumlah cadangan bauksit mencapai 1,2 milyar ton (Pusat Sumber Daya Geologi, 2015). Dalam upaya mendapatkan hasil yang optimal, bauksit perlu ditingkatkan kadarnya dengan cara pencucian dan scrubbing untuk menghilangkan pengotornya, karena pengotor ini dapat mengurangi kapasitas pengolahan dan pemanfaatan bauksit (Husaini $d k k ., 2015)$. Bijih bauksit dapat dimanfaatkan dalam berbagai bidang, salah satunya adalah sebagai bahan baku pembuatan koagulan untuk penjernihan/pemurnian air (water purification) (Yilmaz dkk., 2015). Koagulan yang dapat dihasilkan dari bahan baku bauksit antara lain aluminium sulfat (tawas), fero sulfat, dan poli aluminium klorida (PAC). PAC dapat dibuat dari bijih bauksit setelah bijih bauksit tersebut diubah menjadi alumina hidrat melalui proses digesting dan hidrolisis (Husaini $\left.d k k_{.}, 2015\right)$. Sampai saat ini ketersediaan alumina hidrat sebagai salah satu bahan baku utama untuk pembuatan koagulan masih belum banyak diproduksi di dalam negeri. Oleh karena itu, pada penelitian ini telah dilakukan proses hidrolisis larutan natrium aluminat dengan menggunakan biang untuk mendapatkan alumina hidrat yang memiliki kualitas yang baik.

Penelitian ini merupakan pengembangan dari penelitian sebelumnya yaitu pembuatan larutan natrium aluminat melalui digesting bauksit dengan soda kostik pada skala pilot (Husaini $d k k ., 2013)$. Proses digesting bauksit dengan larutan $\mathrm{NaOH}$ pada konsentrasi tertentu (150-200 g/L) merupakan rangkaian dari process Bayer yang dioperasikan mulai suhu $120{ }^{\circ} \mathrm{C}$ sampai dengan $270^{\circ} \mathrm{C}$ yang tergantung pada jenis bauksitnya. Di bawah kondisi tersebut, sebagian besar kandungan aluminium dalam bijih bauksit akan larut yang menghasilkan larutan natrium aluminat, dan padatan tidak larut akan menjadi red mud (Abdel-Aal, 2016). Bauksit juga dapat dilarutkan dalam asam pada temperatur relatif tinggi $\left(\geq 180^{\circ} \mathrm{C}\right)$ dan tekanan rendah $(\leq 30$ bar) (Rüdel dkk., 2011). Dalam pelarutan bauksit dengan asam, logam-logam yang terkandung dalam bijih bauksit seperti alumina, oksida besi akan terlarut, akan tetapi logam-logam dalam bijih bauksit tidak dapat larut dalam air atau pelarut organik (Koki, 2015).

Larutan natrium aluminat termasuk garamgaram aluminium, aluminat, alkohol dan dari logam aluminium dapat diproses lebih lanjut menjadi aluminium hidroksida $\left[\mathrm{Al}(\mathrm{OH})_{3}\right]$ melalui proses pengendapan atau hidrolisis (Bray, 2017). Dalam proses hidrolisis ini, adanya perubahan kesetimbangan ion hidrogen menyebabkan terjadinya reaksi asam atau basa di dalam larutan (Nazarov, 2016). Metode pengendapan $\mathrm{Al}(\mathrm{OH})_{3}$ dari garamnya dapat dilakukan dengan penambahan amonia, atau dari larutan natrium aluminat yang ditambahkan asam ke dalamnya (Metson, 2011).

Ada beberapa penelitian mengenai pembentukan alumina hidrat, salah satunya adalah pengendapan alumina hidrat dengan melalui sistem supersaturated dengan asam nitrat (Dimitrios dan Athina, 2005). Pada penelitian tersebut diperoleh hasil, bahwa secara umum alumina hidrat (bayerit) terbentuk seketika setelah penambahan larutan asam nitrat dan secara berangsur-angsur dapat membentuk gibsit.

Aluminium hidroksida $\mathrm{Al}(\mathrm{OH})_{3}$ juga dapat diperoleh dengan menambahkan formalin ke dalam larutan natrium aluminat pada suhu kamar atau titik didihnya selama 5-30 menit dan diaduk secara tetap, kemudian diendapkan selama 5-40 menit. $\mathrm{Al}(\mathrm{OH})_{3}$ kering diperoleh dari hasil filtrasi dengan cara dicuci dengan aseton dan dipanaskan dalam furnace pada suhu $250^{\circ} \mathrm{C}$ (Hayrapetyan $d k k ., 2006$ ). Dari berbagai penelitian tersebut dapat dilihat, bahwa rangkaian proses pembuatan alumina hidrat cukup rumit karena itu pada penelitian ini mencoba mencari alternatif lain dengan menggunakan biang dari $\mathrm{Al}(\mathrm{OH})_{3}$ itu sendiri.

Biang yang digunakan pada proses hidrolisis larutan natrium aluminat ini berfungsi sebagai inti kristal untuk mengendapkan $\mathrm{Al}(\mathrm{OH})_{3}$ dari larutan tersebut. Jumlah produk $\mathrm{Al}(\mathrm{OH})_{3}$ yang dihasilkan akan semakin banyak dengan penambahan biang ini. Dari berbagai hasil 
penelitian menunjukkan, bahwa penggunaan biang dalam suatu proses hidrolisis cukup berpengaruh, seperti pada penelitian hidrolisis polisakarida dengan menggunakan biang asam jawa (tamarind). Tamarind tersebut dapat menghasilkan silosa yang kemudian dapat dirubah menjadi xylitol (González-Hernández $d k k ., 2017)$.

Tujuan penelitian ini adalah untuk mendapatkan kondisi hidrolisis larutan natrium aluminat yang optimum dengan menggunakan biang
$\mathrm{Al}(\mathrm{OH})_{3}$. Dalam penelitian ini, larutan natrium aluminat yang digunakan diperoleh dari digesting bauksit dengan $\mathrm{NaOH}$, sedangkan biang diperoleh dari hidrolisis larutan natrium aluminat dengan asam sulfat yang sudah melalui proses pencucian dan pemurnian menggunakan hidrosiklon. Percobaan hidrolisis dengan menggunakan biang $\mathrm{Al}(\mathrm{OH})_{3}$ ini dilakukan dengan memvariasikan waktu, kualitas biang dan konsentrasi natrium aluminat.

\section{METODOLOGI}

1. PROSES PEMURNIAN ALUMINA HIDRAT SEBAGAI SEED

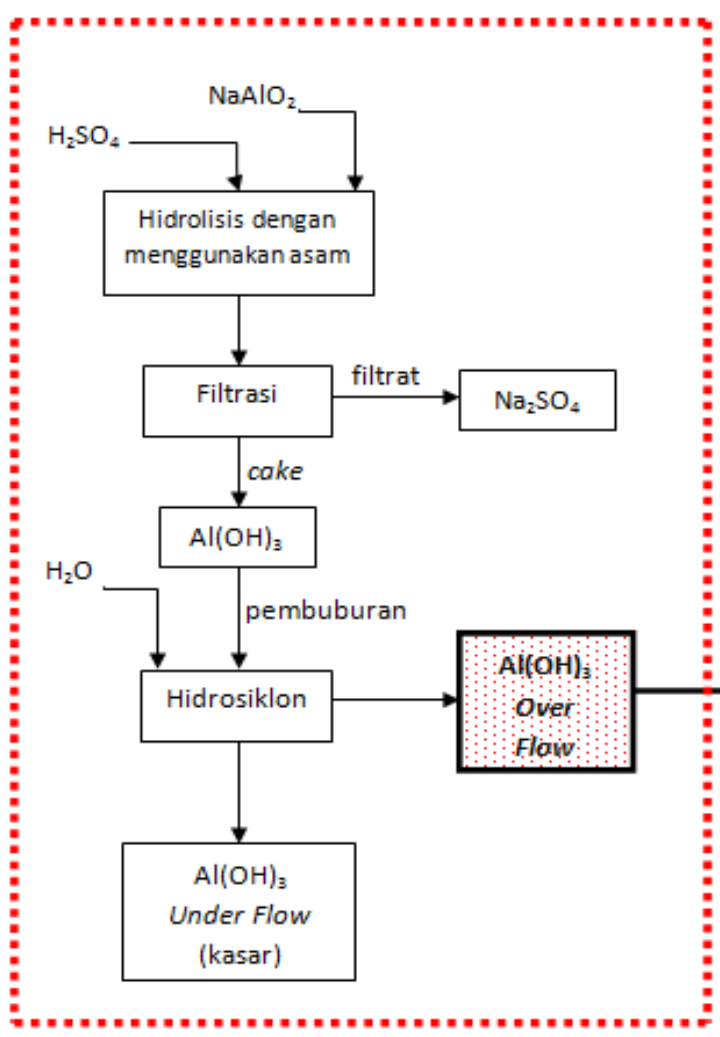

\section{PROSES PEMBUATAN SODIUM ALUMINAT}

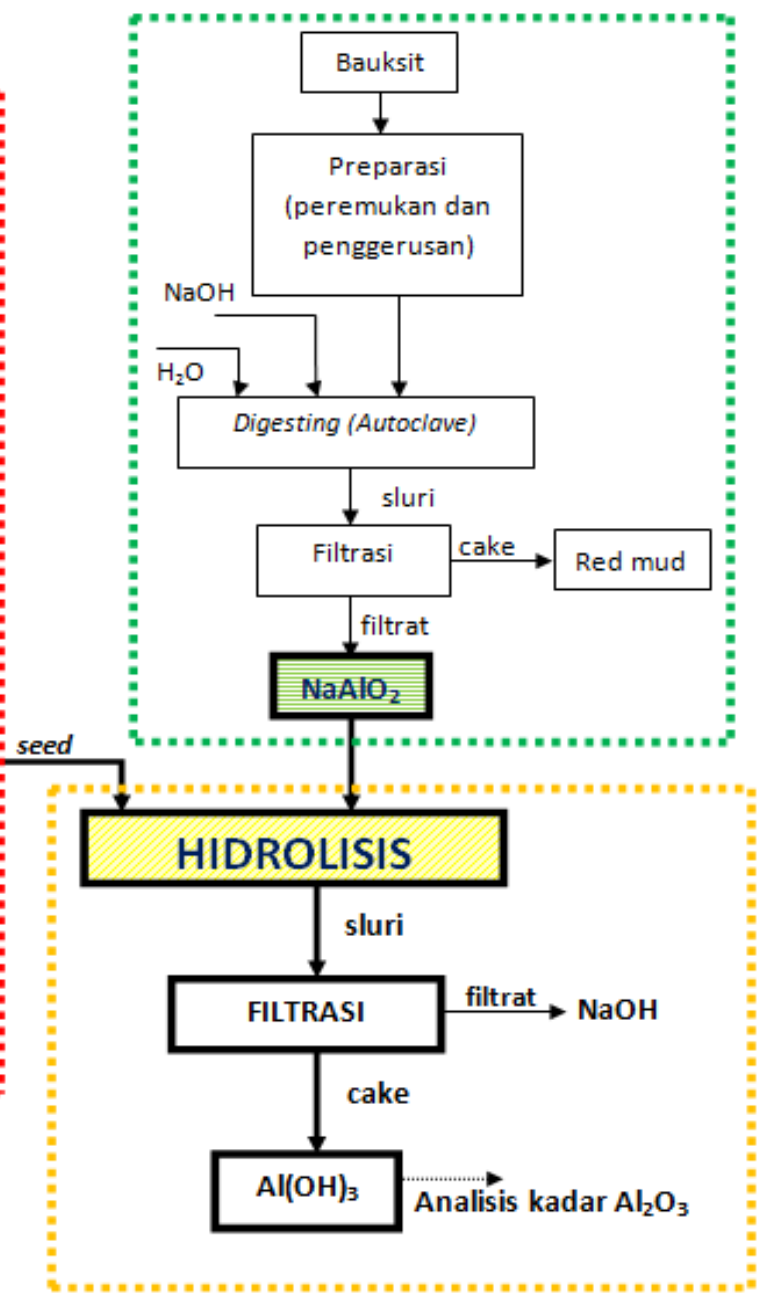

3. PROSES HIDROISIS

Gambar 1. Bagan alir proses hidrolisis dengan biang alumina hidrat 
Percobaan hidrolisis ini dilakukan dalam tiga tahap, yaitu proses pemurnian $\mathrm{Al}(\mathrm{OH})_{3}$ yang digunakan sebagai biang, penyiapan larutan natrium aluminat, dan hidrolisis larutan natrium aluminat dengan menggunakan biang yang telah dibuat.

\section{Pemurnian Alumina Hidrat untuk Biang}

Alumina hidrat yang digunakan sebagai biang diperoleh dari proses hidrolisis natrium aluminat dengan asam sulfat setelah dimurnikan terlebih dahulu (Husaini $d k k$., 2013). Proses pemurnian alumina hidrat dilakukan dengan cara melarutkan pengotor yang menempel pada permukaannya menggunakan air. Alumina hidrat dicampur dengan air dengan persen solid tertentu (5$10 \%)$ kemudian dimasukkan ke dalam sump, dan disirkulasi di dalam sump tersebut dengan menggunakan pompa agar sluri menjadi homogen. Setelah itu sluri dalam sump dipompa melalui hidrosiklon dengan laju alir tertentu, sehingga terjadi pemisahan antara alumina berbutir halus (masuk aliran atas) dan berbutir relatif kasar (masuk aliran bawah) yang sekaligus melarutkan kandungan pengotor. Alumina hidrat pada bagian over flow (berbutir halus) inilah yang selanjutnya digunakan sebagai biang dalam proses hidrolisis.

$\mathrm{Al}(\mathrm{OH})_{3}$ yang digunakan sebagai biang dalam penelitian ini dimurnikan terlebih dahulu dengan cara pencucian lewat hidrosiklon. Hydrocyclone bekerja dengan memanfaatkan interaksi dua gaya yang berlawanan, yaitu gaya sentrifugal dan gaya sentripetal $(\mathrm{Hsu}, \mathrm{Wu}$ dan $\mathrm{Wu}, 2011)$. Adanya dua gaya yang saling berlawanan tersebut menyebabkan partikelpartikel akan terpengaruh sesuai dengan ukuran serta berat jenis partikel. Partikel berukuran kasar dan berat jenis tinggi akan keluar dari bagian bawah (under flow) dan partikel yang berukuran halus dan ringan akan keluar dari bagian atas (over flow) dari hidrosiklon dan percobaan ini dilakukan sebanyak 3 kali. Produk aliran atas tersebut digunakan sebagai biang pada penelitian ini, karena memiliki kemurnian yang lebih tinggi yaitu memiliki kadar 96,51\% $\quad \mathrm{Al}_{2} \mathrm{O}_{3}$ dibandingkan dengan produk aliran bawah yang memiliki kadar $95,59 \% \quad \mathrm{Al}_{2} \mathrm{O}_{3}$ yang merupakan hasil pemisahan dari hidrosiklon. Penggunaan biang pada penelitian ini adalah untuk memperpendek waktu hidrolisis dan meningkatkan produk $\mathrm{Al}(\mathrm{OH})_{3}$ saat hidrolisis berlangsung.

\section{Penyiapan Larutan Natrium Aluminat}

Proses pembuatan larutan natrium aluminat dilakukan dengan tahapan sebagai berikut: bauksit dipreparasi dengan cara diremuk, digerus, setelah itu dilarutkan (digesting) di dalam autoclave dengan mencampurkan $\mathrm{NaOH}$ dan air ke dalamnya. Hasil digesting ini berupa sluri yang merupakan campuran larutan natrium aluminat dengan red mud. Untuk memisahkan larutan natrium aluminat dari red mud, sluri dipompa melalui filter press, sehingga didapat larutan natrium aluminat jernih yang digunakan sebagai bahan baku untuk proses hidrolisis.

\section{Proses Hidrolisis Larutan Natrium Aluminat}

Bahan baku yang digunakan meliputi biang dari hasil pemurnian aluminium hidrat, larutan natrium aluminat dan air dalam perbandingan tertentu. Proses hidrolisis ini dilakukan dengan cara memasukkan larutan natrium aluminat dan air dengan volume dan kadar $\mathrm{Al}_{2} \mathrm{O}_{3}$ tertentu ke dalam tangki hidrolisis, setelah itu biang dimasukkan ke dalam reaktor yang berisi larutan tersebut dan dipanaskan pada suhu \pm $70^{\circ} \mathrm{C}$ dalam keadaan teraduk dan dibiarkan selama 72 jam. Suhu dipertahankan agar tidak melebihi $100^{\circ} \mathrm{C}$, karena alumina hidrat akan kembali membentuk natrium aluminat (Yeboah $d k k .$, 2014). Selama proses berlangsung, percontoh dalam reaktor diambil dalam selang waktu tertentu (tiap 3 jam atau 6 jam) dengan konsentrasi umpan yang berbeda untuk dianalisis kandungan $\mathrm{Al}_{2} \mathrm{O}_{3}$ nya, sehingga tingkat penurunan kadar $\mathrm{Al}_{2} \mathrm{O}_{3}$ nya dapat diketahui. Analisis kimia dilakukan setelah sluri disaring dengan menggunakan filter press. Sedangkan untuk padatannya dikeringkan dan ditimbang. Adapun rumus untuk perhitungan hidrolisisnya adalah sebagai berikut :

$\%$ Hidrolisis $=$

$\left[\mathrm{Al}_{2} \mathrm{O}_{3}\right.$ umpan $-\mathrm{Al}_{2} \mathrm{O}_{3}$ dalam filtrat saat sampling]x $100 \%$ $\mathrm{Al}_{2} \mathrm{O}_{3}$ dalam umpan 


\section{HASIL DAN PEMBAHASAN}

\section{Pemurnian Alumina Hidrat untuk Biang}

Pada penelitian ini, alumina hidrat yang akan digunakan sebagai biang perlu dimurnikan terlebih dahulu.

Alumina hidrat yang digunakan sebagai biang pada proses hidrolisis harus memiliki kualitas yang baik, terutama kadar alumina dan ukuran butirnya. Untuk mendapatkan kualitas biang yang baik, proses pemurnian alumina hidrat dengan menggunakan hidrosiklon telah dilakukan yang hasilnya dapat dilihat pada Tabel 1. Kadar alumina dalam alumina hidrat dapat ditingkatkan dari semula sekitar 58,70\% menjadi $62,79-63,1 \% \quad \mathrm{Al}_{2} \mathrm{O}_{3}$ pada produk aliran atas (over flow) dan 59-62,5\% $\mathrm{Al}_{2} \mathrm{O}_{3}$ pada aliran bawah (under flow). Dalam proses pemurnian alumina hidrat ini digunakan air sebagai media pencuci, sehingga semua pengotor yang menempel pada permukaan alumina hidrat seperti $\mathrm{NaOH}, \mathrm{NaAlO}_{2}$, dan pengotor lainnya akan terbuang, dan terpisah dari produk baik over flow maupun under flow-nya. Berdasarkan neraca massa, kandungan alumina dalam alumina hidrat yang digunakan sebagai umpan (feed) terjadi kenaikan kadar $\mathrm{Al}_{2} \mathrm{O}_{3}$ mencapai 61,59$62,58 \%$. Hal ini karena kandungan pengotor yang sudah terbuang tidak diperhitungkan lagi dalam perhitungan neraca masa ini. Meskipun pengotor tidak sepenuhnya dapat dipisahkan selama proses namun dapat berpengaruh terhadap hasil akhir atau produk ( $\mathrm{Hsu}, \mathrm{Wu}$ dan $\mathrm{Wu}$, 2011). Pengotor juga bisa dipengaruhi oleh variabel operasi hidrosiklon antara lain: tekanan operasi, laju alir umpan, densitas padatan, persen padatan, densitas media liquid, dan viskositas media cairan (Nirwansyah, 2014). Kondisi atau ukuran partikel umpan perlu diperhatikan dalam pencucian ini, karena ukuran partikel sangat mempengaruhi efisiensi pemisahan hidrosiklon (Hsu, Wu dan Wu, 2011). Dari hasil pencucian ini didapat data bahwa produk aliran atas dari hidrosiklon memiliki ukuran butir lebih halus dan kadar alumina yang lebih tinggi dibandingkan dengan produk aliran bawahnya, sehingga lebih cocok untuk digunakan sebagai biang pada proses hidrolisis.

\section{Penyiapan Larutan Natrium Aluminat}

Larutan natrium aluminat yang digunakan merupakan hasil penelitian yang sudah dilakukan sebelumnya yaitu digesting bauksit dengan soda kaustik pada skala pilot. Percobaan digesting dilakukan dengan menggunakan bauksit tercuci dan sudah dipreparasi terlebih dahulu sampai berukuran -150 mesh.

Sluri yang dihasilkan difiltrasi menghasilkan larutan natrium aluminat dan red mud. Larutan yang dihasilkan memiliki berat jenis berkisar 1,050-1,077 g/mL dengan $\mathrm{pH}$ sekitar 13. Baik umpan, larutan maupun red mud nya selanjutnya dianalisis kandungan $\mathrm{Al}_{2} \mathrm{O}_{3}$, $\mathrm{Fe}_{2} \mathrm{O}_{3}, \mathrm{SiO}_{2}$, dan $\mathrm{TiO}_{2}$. Hasil analisis untuk $\mathrm{Fe}_{2} \mathrm{O}_{3}, \mathrm{SiO}_{2}$, dan $\mathrm{TiO}_{2}$ dalam red mud berada di bawah $15 \%$ yang berarti pengotor dalam proses sudah minimum, apabila kandungan dari pengotor tersebut masih di atas 20\% maka akan sangat berpengaruh pada proses hidrolisis yang menyebabkan proses hidrolisis rendah. Persen ekstraksi tertinggi diperoleh dengan menggunakan berat $\mathrm{NaOH}$ (kemurnian 99\%) 36,75 kg (ekses $\mathrm{NaOH}$ sekitar 30\%) untuk $63 \mathrm{~kg}$ bauksit yang menghasilkan persen ektraksi $\mathrm{Al}_{2} \mathrm{O}_{3}$ sebesar $75,33 \%$.

Reaksi proses digesting bauksit dengan $\mathrm{NaOH}$ sebagai berikut:

$\mathrm{Al}_{2} \mathrm{O}_{3} .3 \mathrm{H}_{2} \mathrm{O}+2 \mathrm{NaOH}_{\mathrm{aq}} \rightarrow 2 \mathrm{NaAlO}_{2}+4$

$\mathrm{H}_{2} \mathrm{O}\left(110-150{ }^{\circ} \mathrm{C}\right)$.................................. (1)

Reaksi Hidrolisis dengan penambahan biang $\mathrm{Al}(\mathrm{OH})_{3}$ sebagai berikut:

$\mathrm{Na}_{2} \mathrm{O} . \mathrm{Al}_{2} \mathrm{O}_{3}+4 \mathrm{H}_{2} \mathrm{O} \rightarrow 2 \mathrm{Al}\left(\mathrm{OH}_{3}\right)+\mathrm{H}_{2} \mathrm{O}$

Semakin tinggi berat $\mathrm{NaOH}$ yang ditambahkan, persen ekstraksi $\mathrm{Al}_{2} \mathrm{O}_{3}$ semakin tinggi. Variasi ekses $\mathrm{NaOH}$ dilakukan untuk mengetahui pengaruh dari berat $\mathrm{NaOH}$ terhadap persen hidrolisis yang akan dihasilkan (Husaini dkk., 2011).

\section{Proses Hidrolisis Larutan Natrium Aluminat}

Hasil hidrolisis larutan natrium aluminat untuk pengambilan percontoh tiap 6 jam pada Tabel 2 menunjukkan bahwa kadar alumina dalam alumina berfluktuatif. Hal ini disebabkan oleh terlarutnya kembali alumina 
hidrat yang sudah terbentuk dengan $\mathrm{NaOH}$ yang ada dalam larutan natrium aluminat pada kondisi suhu percobaan. Konsentrasi alumina pada percobaan ini turun dari 166,4 $\mathrm{g} / \mathrm{l}$ menjadi $62,5 \mathrm{~g} / \mathrm{l}$, hal ini terjadi karena pengaruh dari ekses $\mathrm{NaOH}$ yang digunakan. Untuk mengetahui pengaruh dari ekses $\mathrm{NaOH}$ yang digunakan dalam proses hidrolisis ini, dilakukan percobaan hidrolisis kedua dengan menambah jumlah ekses $\mathrm{NaOH}$ dan dengan variasi pengambilan percontoh yang berbeda yaitu setiap 3 jam.

Pada penelitian ini proses hidrolisis dilakukan dengan memvariasikan waktu pengambilan percontoh. Hasil data percobaan dapat dilihat pada Tabel 2 dan Tabel 3.

Tabel 1. Percobaan hidrosiklon untuk pemurnian biang

\begin{tabular}{|c|c|c|c|c|}
\hline \multirow{2}{*}{ No } & \multirow{2}{*}{ Data yang diperoleh } & \multicolumn{3}{|c|}{ No. Percobaan } \\
\hline & & P1 & $\mathrm{P} 2$ & P3 \\
\hline & Umpan (kg) & & & \\
\hline 1 & Berat basah $(\mathrm{kg})$ & 60,80 & 85,26 & 72,67 \\
\hline 2 & Kadar air (\%) & 37,10 & 43,29 & 46,93 \\
\hline 3 & Berat kering $(\mathrm{Kg})$ & 38,24 & 48,35 & 38,57 \\
\hline 4 & - Kadar $\mathrm{Al}_{2} \mathrm{O}_{3}$ dalam umpan (\%) & 62,58 & 61,59 & 62,32 \\
\hline 5 & $\operatorname{Air}(\mathrm{L})$ & 80,88 & 75,83 & 80,72 \\
\hline & Kondisi Proses & & & \\
\hline 6 & $\%$ Solid & 32 & 38,9 & 32,3 \\
\hline 7 & Waktu (menit) & 6,4 & 8,5 & 8,5 \\
\hline 8 & $\begin{array}{l}\text { Laju alir (L/menit) } \\
\text { Hasil Proses }\end{array}$ & 15,63 & 11,76 & 11,76 \\
\hline & Over Flow & & & \\
\hline 9 & Produk Halus (Over flow) (kg)--> untuk Biang & 72,5 & 51 & 52 \\
\hline 10 & - Kadar air dalam OF $(\%)$ & 14,61 & 59,97 & 54,28 \\
\hline 11 & - Berat OF kering $(\mathrm{kg})$ & 10,59 & 30,59 & 28,22 \\
\hline 12 & - Kadar $\mathrm{Al}_{2} \mathrm{O}_{3}$ dalam OF (\%) & 62,79 & 63,1 & 63,1 \\
\hline 13 & - Berat $\mathrm{Al}_{2} \mathrm{O}_{3}$ dalam OF kering $(\mathrm{kg})$ & 6,65 & 19,30 & 17,81 \\
\hline 14 & $\begin{array}{l}\text { - Kemurnian } \mathrm{Al}(\mathrm{OH})_{3} \text { dalam OF }(\%) \\
\text { Under Flow }\end{array}$ & 96,03 & 96,51 & 96,51 \\
\hline 15 & Produk Kasar (Under flow) (kg) & 73 & 51 & 17 \\
\hline 16 & - Kadar air under flow $(\%)$ & 37,88 & 34,84 & 60,84 \\
\hline 17 & - Berat UF kering $(\mathrm{kg})$ & 27,65 & 17,77 & 10,34 \\
\hline 18 & - Kadar $\mathrm{Al}_{2} \mathrm{O}_{3}$ dalam UF (\%) & 62,5 & 59 & 60,2 \\
\hline 19 & - Berat $\mathrm{Al}_{2} \mathrm{O}_{3}$ dalam UF kering (kg) & 17,28 & 10,48 & 6,23 \\
\hline 20 & - Kemurnian $\mathrm{Al}(\mathrm{OH})_{3}$ dalam UF $(\%)$ & 95,59 & 90,24 & 92,07 \\
\hline
\end{tabular}

Tabel 2. Percobaan hidrolisis dengan menggunakan biang selama 72 jam dengan frekuensi pengambilan percontoh tiap 6 jam

\begin{tabular}{ccccc}
\hline No & $\begin{array}{c}\text { Suhu sluri dalam } \\
\text { reaktor }\left({ }^{\circ} \mathrm{C}\right)\end{array}$ & $\begin{array}{c}\text { Lama proses } \\
(\text { jam })\end{array}$ & $\begin{array}{c}\text { Kadar } \mathrm{Al}_{2} \mathrm{O}_{3} \text { dalam } \\
\text { filtrat di reaktor }(\mathrm{g} / \mathrm{L})\end{array}$ & Persen hidrolisis $(\%)$ \\
\hline 1 & 25 & 0 & 152,91 & 0,00 \\
2 & $80-90$ & 6 & 166,40 & $-8,82$ \\
3 & $80-90$ & 12 & 147,60 & 3,47 \\
4 & $80-90$ & 18 & 124,30 & 14,01 \\
5 & $80-90$ & 24 & 142,80 & 9,31 \\
6 & $70-90$ & 30 & 112,80 & 11,31 \\
7 & $60-78$ & 36 & 88,00 & 27,48 \\
8 & $60-60$ & 42 & 73,30 & 42,37 \\
9 & $60-60$ & 48 & 83,80 & 34,11 \\
10 & $59-60$ & 54 & 66,30 & 42,86 \\
11 & $59-59$ & 60 & 65,70 & 43,38 \\
12 & $59-60$ & 66 & 62,20 & 46,39 \\
13 & $60-61$ & 72 & 62,50 & 46,13 \\
\hline
\end{tabular}




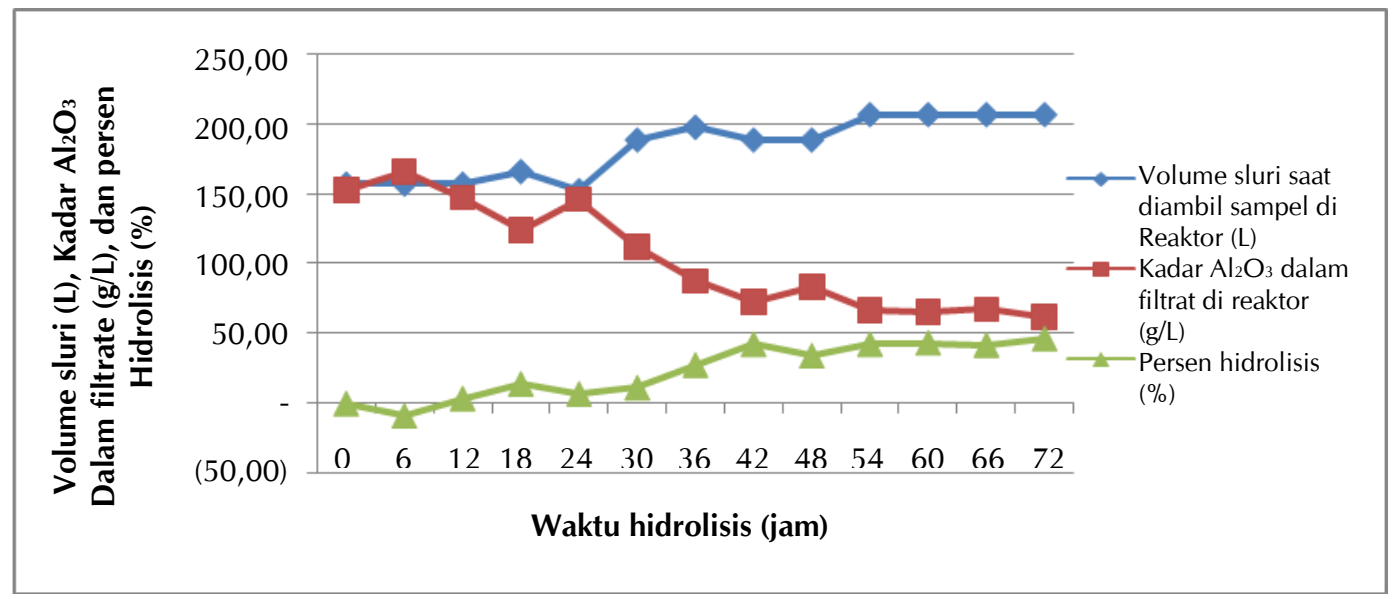

Gambar 2. Hasil percobaan hidrolisis dengan biang (frekuensi pengambilan percontoh tiap 6 jam)

Dari Gambar 2 terlihat bahwa kadar $\mathrm{Al}_{2} \mathrm{O}_{3}$ dalam larutan natrium aluminat berfluktuasi dan cenderung menurun, hal ini terjadi karena terlarutnya kembali alumina hidrat. Persen hidrolisis yang didapatkan terlihat semakin tinggi pada akhir hidrolisis, ini merupakan pengaruh dari ekses $\mathrm{NaOH}$ yang digunakan sekitar $>15 \%$. Volume sluri naik karena penambahan air yang bertujuan untuk membantu proses hidrolisis dan menjaga konsentrasi $\mathrm{NaOH}$ agar tidak pekat akibat penguapan. Apabila konsentrasi $\mathrm{NaOH}$ pekat maka akan melarutkan kembali $\mathrm{Al}_{2} \mathrm{O}_{3}$ yang telah terbentuk emenjadi natrium aluminat.

Data hasil percobaan kedua pada Tabel 3, menunjukkan hasil pengambilan percontoh tiap 3 jam. Pada percobaan hidrolisis yang pertama (Tabel 2), konsentrasi alumina dalam larutan turun dari 166,4 g/L menjadi $62,5 \mathrm{~g} / \mathrm{L}$ setelah proses hidrolisis berlangsung 72 jam. Sedangkan pada percobaan kedua (Tabel 3), konsentrasi alumina pada akhir hidrolisis setelah 72 jam, hanya dapat diturunkan dari $161,3 \mathrm{~g} / \mathrm{L}$ menjadi 119,21g/L. Kedua percobaan ini sesuai dengan penelitian sebelumnya yang menyebutkan bahwa untuk proses presipitasi aluminat, hidrolisis dilakukan pada kisaran suhu antara $55-60^{\circ} \mathrm{C}$, dan rentang waktu 50-72 jam (Matori et al., 2012). Persen hidrolisis pada percobaan kedua lebih rendah dibandingkan dengan percobaan pertama. Hal ini disebabkan oleh ekses $\mathrm{NaOH}$ pada larutan natrium aluminat yang digunakan pada percobaan ke dua lebih tinggi dibandingkan dengan yang digunakan pada percobaan pertama yaitu masing-masing $>30 \%$ dan $15 \%$. Jadi jelas bahwa ekses $\mathrm{NaOH}$ yang terlalu berlebihan pada saat proses digesting berlangsung, larutan natrium aluminat yang dihasilkan kurang baik untuk dihidrolisis dengan menggunakan biang walaupun dengan ekses $\mathrm{NaOH}$ yang lebih tinggi pada proses digesting memberikan persen ekstraksi alumina yang lebih tinggi.

Tabel 3. Percobaan hidrolisis menggunakan biang selama 72 jam dengan frekuensi pengambilan percontoh tiap 3 jam

\begin{tabular}{ccccc}
\hline No & $\begin{array}{c}\text { Suhu sluri dalam } \\
\text { reaktor }\left({ }^{\circ} \mathrm{C}\right)\end{array}$ & $\begin{array}{c}\text { Lama proses } \\
\text { (jam) }\end{array}$ & $\begin{array}{c}\text { Kadar } \mathrm{Al}_{2} \mathrm{O}_{3} \text { dalam } \\
\text { filtrat di reaktor }(\mathrm{g} / \mathrm{L})\end{array}$ & Persen hidrolisis (\%) \\
\hline 1 & $25-60$ & 0 & 161,3 & 0,00 \\
2 & 60 & 3 & 165,11 & 2,36 \\
3 & 60 & 6 & 155,23 & 3,76 \\
4 & 58 & 9 & 147,58 & 8,50 \\
5 & 60 & 12 & 141,53 & 12,26 \\
6 & 52 & 15 & 137,06 & 15,03 \\
7 & 58 & 18 & 139,93 & 13,25 \\
8 & 56 & 21 & 145,67 & 9,69 \\
9 & 54 & 24 & 120,81 & 35,65 \\
\hline
\end{tabular}




\begin{tabular}{ccccc}
\hline No & $\begin{array}{c}\text { Suhu sluri dalam } \\
\text { reaktor }\left({ }^{\circ} \mathrm{C}\right)\end{array}$ & $\begin{array}{c}\text { Lama proses } \\
\text { (jam) }\end{array}$ & $\begin{array}{c}\text { Kadar } \mathrm{Al}_{2} \mathrm{O}_{3} \text { dalam } \\
\text { filtrat di reaktor }(\mathrm{g} / \mathrm{L})\end{array}$ & Persen hidrolisis (\%) \\
\hline 10 & 60 & 27 & 126,86 & 21,35 \\
11 & 58 & 30 & 121,44 & 24,71 \\
12 & 53 & 33 & 104,23 & 35,38 \\
13 & 52 & 36 & 112,84 & 30,04 \\
14 & 60 & 39 & 114,11 & 29,25 \\
15 & 57 & 42 & 112,84 & 31,69 \\
16 & 58 & 45 & 114,75 & 30,53 \\
17 & 58 & 48 & 106,46 & 34,00 \\
18 & 59 & 51 & 112,52 & 31,88 \\
19 & 58 & 54 & 106,46 & 34,00 \\
20 & 58 & 57 & 110,93 & 32,84 \\
21 & 56 & 60 & 106,46 & 34,00 \\
22 & 62 & 63 & 137,06 & 15,03 \\
23 & 62 & 66 & 137,70 & 14,63 \\
24 & 56 & 69 & 130,05 & 21,27 \\
25 & 56 & 72 & 119,21 & 27,83 \\
\hline
\end{tabular}

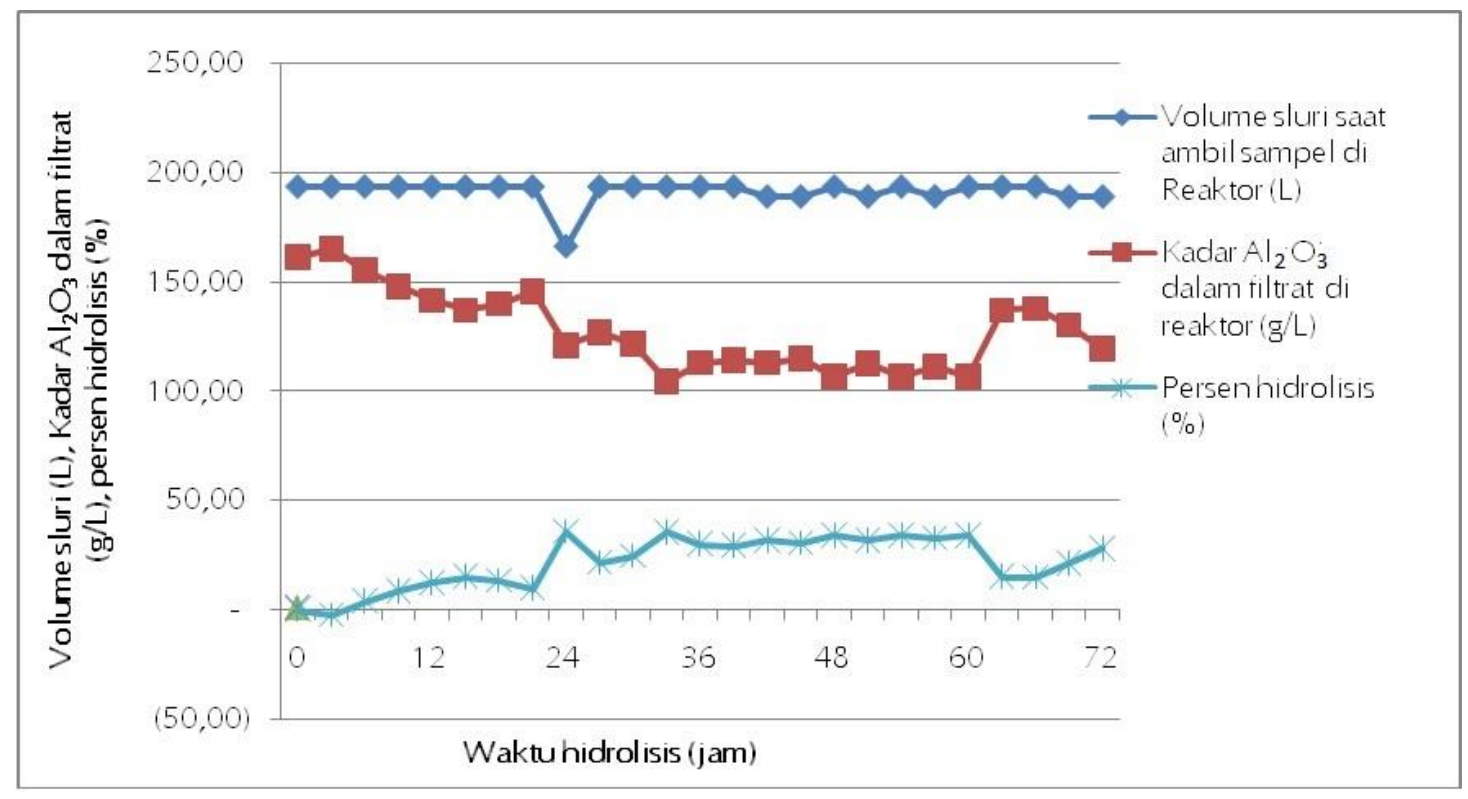

Gambar 3. Hasil percobaan hidrolisis dengan biang (frekuensi pengambilan percontoh tiap 3 jam)

Dari Gambar 3 terlihat bahwa kadar $\mathrm{Al}_{2} \mathrm{O}_{3}$ dalam larutan natrium aluminat juga berfluktuasi dan cenderung menurun sama dengan percobaan pertama. Ada penambahan air pada sluri di percobaan kedua ini namun jumlahnya tidak sebanyak pada percobaan pertama. Hal ini dilakukan untuk melihat pengaruh dari kepekatan $\mathrm{NaOH}$ terhadap persen hidrolisis. Terbukti bahwa pada percobaan kedua lebih rendah dibandingkan dengan percobaan pertama, karena $\mathrm{Al}_{2} \mathrm{O}_{3}$ terlarut kembali menjadi natrium aluminat. Hal itu dapat dilihat pada jam ke 24, volume sluri turun yang menyebabkan kadar $\mathrm{Al}_{2} \mathrm{O}_{3}$ menurun.
Hasil akhir percobaan hidrolisis dengan biang setelah 72 jam, baik untuk frekuensi pengambilan percontoh setiap 3 jam maupun 6 jam dapat dilihat pada Tabel 4. Percobaan pertama, kondisi percobaannya dapat dilihat pada Tabel 3 yang menghasilkan produk alumina hidrat sebesar $12,59 \mathrm{~kg}$ (di luar berat biang yang ditambahkan) atau memberikan persen hidrolisis sebesar $59,82 \%$. Sedangkan untuk percobaan kedua menghasilkan produk alumina hidrat sebesar 22,22 kg (di luar berat biang yang ditambahkan) atau memberikan persen hidrolisis sebesar $46,63 \%$. 
Proses Hidrolisis Larutan Natrium Alumina dengan Menggunakan Biang Aluminium Hidroksida, Husaini dkk.

Tabel 4. Hasil akhir percobaan hidrolisis dengan biang setelah 72 jam

\begin{tabular}{|c|c|c|c|}
\hline \multirow{2}{*}{ No } & \multirow{2}{*}{ Data yang diperoleh } & \multicolumn{2}{|c|}{ No. Percobaan } \\
\hline & & Pertama & Kedua \\
\hline 1 & Frekuensi pengambilan sampel & 6 jam & 3 jam \\
\hline 2 & Berat produk + biang $\mathrm{Al}(\mathrm{OH})_{3}$ basah $(\mathrm{kg})$ & 124 & 124 \\
\hline 3 & Kadar air produk $\mathrm{Al}(\mathrm{OH})_{3}(\%)$ & 51,87 & 45,49 \\
\hline 4 & Berat produk + biang $\mathrm{Al}(\mathrm{OH})_{3}$ kering $(\mathrm{kg})$ & 53,91 & 67,59 \\
\hline 5 & Kadar $\mathrm{Al}_{2} \mathrm{O}_{3}$ dalam produk $\mathrm{Al}(\mathrm{OH})_{3}$ kering $(\%)$ & 59,60 & 58,70 \\
\hline 6 & Volume sisa filtrat $(\mathrm{L})$ & 52,00 & 164,66 \\
\hline 7 & Kadar $\mathrm{Al}_{2} \mathrm{O}_{3}$ dalam filtrat sisa $(\mathrm{g} / \mathrm{L})$ & 62,00 & 119,21 \\
\hline 8 & Berat biang yang digunakan (kg) & 41,32 & 45,88 \\
\hline 9 & Berat produk $\mathrm{Al}(\mathrm{OH})_{3}$ kering $(\mathrm{kg})$ & 12,59 & 22,22 \\
\hline 10 & Berat $\mathrm{Al}(\mathrm{OH})_{3}$ dalam feed $(\mathrm{kg})$ & 21,05 & 47,65 \\
\hline 11 & Persen hidrolisis (\%) & 59,82 & 46,63 \\
\hline
\end{tabular}

\section{KESIMPULAN}

Larutan natrium aluminat yang diperoleh dari berbagai penambahan $\mathrm{NaOH}$ berlebih masih dapat dihidrolisis dengan mudah dengan cara mengatur banyaknya asam sulfat yang dibutuhkan. Sedangkan untuk hidrolisis dengan menggunakan biang, selain kualitas biang harus baik, kondisi larutan natrium aluminat juga sangat berpengaruh. Bila kelebihan $\mathrm{NaOH}$ terlalu tinggi (ekses di atas $30 \%$ ), agak sulit terjadi hidrolisis. Demikian juga bila kualitas biang kurang baik (kadar rendah dan berukuran butir kasar (60 mesh), proses pengendapan $\mathrm{Al}(\mathrm{OH})_{3}$ sulit berlangsung. Bila kelebihan $\mathrm{NaOH}$ terlalu tinggi, ada kecenderungan alumina hidrat yang sudah terbentuk dapat larut kembali selama proses hidrolisis berlangsung. Hal ini disebabakan proses hidrolisis dilakukan pada suhu antara $60-70^{\circ} \mathrm{C}$ dalam waktu yang relatif lama (sampai 72 jam), sehingga bila konsentrasi $\mathrm{NaOH}$ bebas relatif tinggi, maka $\mathrm{NaOH}$ memiliki kemampuan melarutkan kembali $\mathrm{Al}(\mathrm{OH})_{3}$ yang sudah terbentuk.

\section{DAFTAR PUSTAKA}

Abdel-Aal, E.-S. A. (2016) "Leaching kinetics of gibbsitic bauxite with sodium hydroxide," in Kowalczuk, P. B. and Drzymala, J. (eds.) E3S Web of Conferences, p. 01021. doi: 10.1051/e3sconf/20160801021.

Bray, E. L. (2017) "Bauxite and alumina," in Mineral Commodity Summaries 2017. Reston, Virginia: U.S. Geological Survey, pp. 32-33. Available at: https://minerals.usgs.gov/minerals/pubs/comm odity/bauxite/mcs-2017-bauxi.pdf.

Dimitrios, P. and Athina, K. (2005) "Alumina hydrate precipitates in the system $\mathrm{NaAl}(\mathrm{OH}) 4$ (supersaturated)/HNO3," in Proceedings of European Metallurgical Conference 2005, pp. 1-15. Available at: https://www.researchgate.net/publication/234 107808 Alumina hydrate Precipitates in the _system_NaAIOH4_supersaturatedHNO3.

González-Hernández, J. C., Farías Rosales, L., Zamudio Jaramillo, M. Á., Álvarez-Navarrete, M., Vera Villa, J. C., Martínez Corona, R., Chávez-Parga, M. del C. and Peña, A. (2017) "Chemical hydrolysis of the polysaccharides of the tamarind seed," Journal of the Mexican Chemical Society, 56(4), pp. 395-401. doi: 10.29356/jmcs.v56i4.250.

Hayrapetyan, S. S., Mangasaryan, L. G., Tovmasyan, M. R. and Khachatryan, H. G. (2006) "Precipitation of aluminium hydroxide from natrium aluminate, by treatment with formalin, and preparation of aluminium oxide," Acta Chromatographica, (16), pp. 192-203. Available at: http://www.us.edu.pl/uniwersytet/jednostki/w ydzialy/chemia/acta/ac16/zrodla/15_AC16.pd f.

Hsu, C.-Y., Wu, S.-J. and Wu, R.-M. (2011) "Particles separation and tracks in a hydrocyclone," Tamkang Journal of Science and Engineering, 14(1), pp. 65-70. Available at: http://www2.tku.edu.tw/ tkjse/14-1/08CHE9803 .pdf.

Husaini, Aziz, M., Muta'alim, Yuhelda, Azhari, Pendi, S., Rustrendi, D., Wijaya, K., Gandamanah, I. and Sugandi, B. (2011) Aplikasi proses upgrading bauksit Tayan 
Kalimantan Barat dan pemanfaatan tailing pencuciannya untuk koagulan. Bandung: Puslitbang tekMIRA.

Husaini, Purnomo, H., Cahyono, S. S., Muta'alim, Soenara, T., Supriyanto, B. A., Wahyudi, A., Subiantoro, Sugandi, B., Pendi, S., Permana, A. S., Prakosa, A., Sudjarwo, Wijaya, K. and Widodo (2013) Peningkatan kadar dan pemrosesan bauksit bernilai tambah Kalimantan Barat serta pemanfaatan tailingnya. Bandung: Puslitbang tekMIRA.

Husaini, Purnomo, H., Suganal, Cahyono, S. S., Soenara, T., Supriyanto, B. A., Subiantoro, Azhari, Amalia, D., Sugiarti, S., Irfan, Ramanda, Y., Rahmat, Sugandhi, B., Dianawati, E. A., Permana, A. S., Pendi, S., Fatimah, T. S., Alamanda, N., Wijaya, K., Sulistyo, R. S. and Hidayat, A. T. (2015) Persiapan pembangunan demo plant rotary drum scrubber 50 ton/jam dan optimalisasi PAC dan tawas dari tailing washed bauksit. Bandung: Puslitbang tekMIRA.

Koki, I. B. (2015) "Efficiencies of acid digestion/leaching techniques in the determination of iron concentrations in soils from Challawa Industrial Estate Kano, Nigeria," Merit Research Journal of Environmental Science and Toxicology, 3(5), pp. 65-71. Available at: http://meritresearchjournals.org/est/content/20 15/May/Koki.pdf.

Matori, K. A., Wah, L. C., Hashim, M., Ismail, I. and Mohd Zaid, M. H. (2012) "Phase transformations of $\alpha$-alumina made from waste aluminum via a precipitation technique," International Journal of Molecular Sciences, 13(12), pp. 1681216821. doi: 10.3390/ijms131216812.

Metson, J. B. (2011) "Production of alumina," in Fundamentals of Aluminium Metallurgy. Elsevier, pp. 23-48. doi: 10.1533/9780857090256.1.23.
Nazarov, M. N. (2016) "Hydrolysis of salts of distinct nature," Oil and Gas Business, (3), pp. 366-401. doi: 10.17122/ogbus-2016-3366-401.

Nirwansyah, I. (2014) Pemodelan sirkit SAG Mill 2cyclone pack di pabrik pengolahan emas PT Nusa Halmahera Minerals dengan model regresi linear. Institut Teknologi Bandung.

Pusat Sumber Daya Geologi (2015) Executive Summary Pemutakhiran Data dan Neraca Sumber Daya Mineral Status 2015. Bandung: Pusat Sumber Daya Geologi. Available at: http://psdg.geologi.esdm.go.id/Neraca/2015/e xecutive summary neraca mineral 2015.pdf.

Rüdel, H., Kösters, J., Homrighausen, D. and Hansknecht, D. (2011) "Guidelines for chemical analysis: Digestion of environmental samples, V 2.0.2." Auf dem Aberg: Fraunhofer Institute for Molecular Biology and Applied Ecology, p. 6. Available at:

https://www.ime.fraunhofer.de/content/dam/i me/en/documents/AE/SOP_Digestion.pdf.

Yeboah, I., Addai, E. K., Acquah, F. and Tulashie, S. K. (2014) "A comparative study of the super cooling and carbonization processes of the gibbsitic Ghanian bauxite," International Journal of Engineering Science and Innovative Technology, 3(6), pp. 76-85. Available at: http://www.ijesit.com/Volume 3/Issue 6/IJESIT201406_10.pdf.

Yilmaz, K., Birol, B., Sarıdede, M. N. and Yiğit, E. (2015) "Pre-beneficiation of low grade diasporic bauxite ore by reduction roasting," International Journal of Materials and Metallurgical Engineering, 9(9), pp. 1084$1087 . \quad$ Available at: https://waset.org/Publication/prebeneficiation-of-low-grade-diasporic-bauxiteore-by-reduction-roasting/10002069. 